\title{
In vitro evaluation of the cyto- and genotoxicity of titanium and titanium-based alloy Ti-6Al-4V used in the manufacture of screw type dental implants - preliminary study
}

Teodora MARCU ${ }^{1}$, Augustin MIHAI $^{2}$, Mihai BURLIBASA ${ }^{2}$, Nicoleta CONSTANTIN ${ }^{3}$, Corina Marilena CRISTACHE², Viorel PERIEANU², Mihaela CHIRILA², Madalina PERIEANU², Madalina MALITA ${ }^{2}$, Radu COSTEA ${ }^{2}$, Raluca COSTEA ${ }^{4}$, Iuliana BABIUC ${ }^{2}$, Gabriela TANASE², Irina Adriana BEURAN², Constantin Florin DRAGAN², Liliana BURLIBASA ${ }^{3}$

1 "Dunarea de Jos" University, Galati, Romania

2 "Carol Davila" University of Medicine and Pharmacy, Bucharest, Romania

${ }^{3}$ Faculty of Biology, University of Bucharest, Romania

${ }^{4}$ Private practice, Brasov, Romania

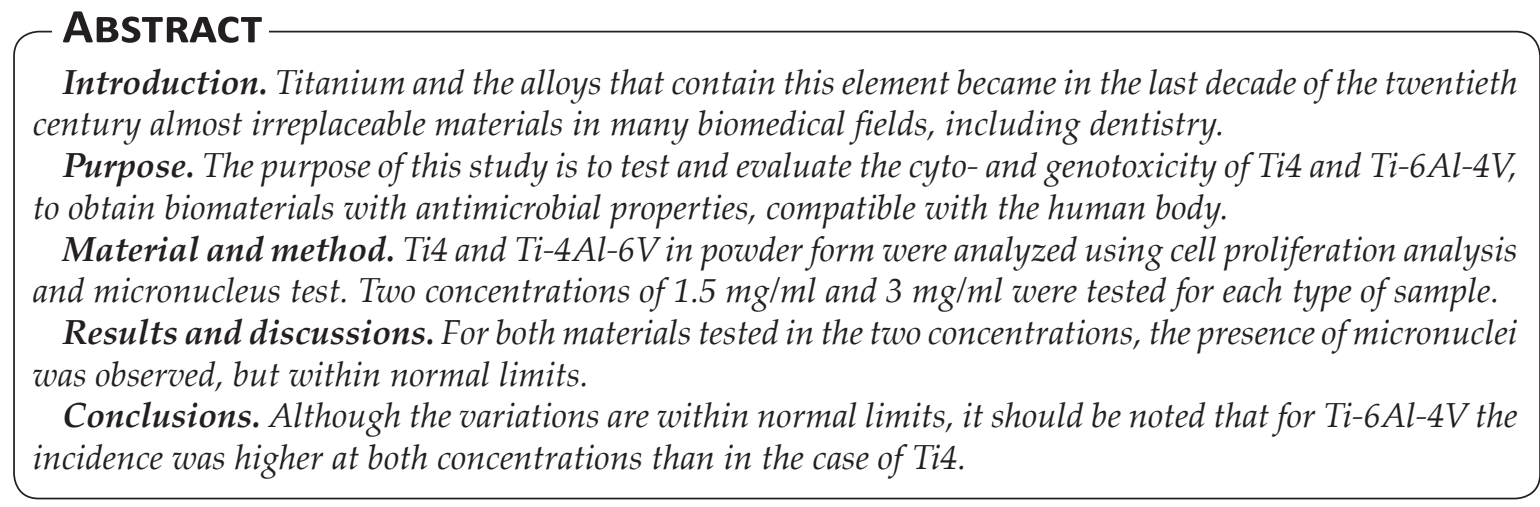

Keywords: Ti4, Ti-6Al-4V, cytotoxicity, genotoxicity

\section{INTRODUCTION}

Titanium and its alloys have many applications in dentistry, being used in almost all areas of this medical specialty: orthodontics, endodontics, dental prosthetics and especially oral implantology, the last two areas including implant-prosthetic rehabilitation. However, it should be emphasized that the use of titanium as well as titanium-based alloys in the biomedical field depends on the biocompatibility of this element, an issue regulated by European Council Directive 93/42/EEC of 14 June 1993 (1).

Thus, titanium and the alloys that contain this element became in the last decade of the twentieth century, but also in these first decades of the twenty-first century, almost irreplaceable materials in many biomedical fields, including dentistry. Specifically, this metallic material attracted the attention of dental researchers through its particularly friendly properties, such as: biocompatibility, low thermal conductivity, 
low density, corrosion resistance, but especially an extremely advantageous price, being almost 4 times lower than that of gold and/or gold-based alloys $(1,2,3)$.

\section{GENERAL DATA}

Both commercially pure titanium and titanium alloys are used for the industrial production of screwtype dental implants.

Commercially pure titanium has a titanium concentration of approximately $99 \%$ with small traces of $\mathrm{N}, \mathrm{C}$, $\mathrm{H}, \mathrm{Fe}$ and $\mathrm{O}$. There are four types of commercially pure titanium also called grades. The differences between the 4 grades are given mainly by the variation of the oxygen concentration, variations that although small have major influences in terms of physical and mechanical properties (4).

At the same time, researchers in metallurgy useful in dental practice, have looked for various formulas to improve the qualities of titanium and alloys with the main component titanium.

The biocompatibility of a material used in dentistry aims in the first phases of testing its cytotoxicity and genotoxicity. Cytotoxicity is the ability of a substance to be toxic to cells, while genotoxicity is characteristic of a substance to damages cellular DNA.

In recent years, numerous studies have been carried out regarding the use of alloys of various types, including titanium-based alloys, as biomaterials and on the evaluation of their genotoxic capacity, on various human and animal cell lines (fibroblasts, dermal cells etc.) $(5,6)$.

\section{PURPOSEANDOBJECTIVESOF THESTUDY}

In conducting this study, commercially pure titanium grade 4 (abbreviated Ti4), but also a titanium-based alloy, namely Ti-6Al-4V were used. The purpose of this study is to test and evaluate the cyto- and genotoxicity of the substances mentioned above, to obtain biomaterials with antimicrobial properties, compatible with the human body.

This practical study is a first in an attempt to evaluate the genotoxic effects of commercially pure titanium grade 4 (abbreviated Ti4) and Ti-6Al-4V alloy on human lymphocytes. The evaluation of genotoxicity was performed by in vitro micronucleus test, standardized and recommended by the OECD (Organization for Economic Co-operation and Development), but adapted and optimized (7). The purpose of this test is to detect micronuclei in the cytoplasm of interphase cells and to calculate their incidence. This test detects the clastogenic and aneugenic activity of some chemical agents in cells that have undergone cell division during or after exposure to the test substance.

\section{MATERIALS AND METHODS}

The study was conducted in collaboration with our colleagues, who work in the Department of Genetics of the Faculty of Biology, University of Bucharest.

Cell proliferation analysis was used to determine the cytotoxicity, while in vitro micronucleus test on the mammalian model (lymphocyte cultures) was used to test genotoxicity.

\section{Materials}

The materials used for this study were: titanium (commercially pure grade 4 - abbreviated Ti4) and Ti-6Al-4V alloy (used for industrial-scale manufacturing of screw-type dental implants), both materials in the form of powders obtained by milling compact blocks.

The materials used for the micronucleus method were the following: lymphocyte cultures; biochemistry tubes BD Vacutainer Sodium Heparin; PB-MAX medium (GIBCO) supplemented with phytohemagglutinin; Bovine Serum Albumin (BSA); amino acids and antibiotics; $\mathrm{KCl}$ solution; 3:1 methanol/ acetic acid solution; Giemsa solution.

As devices, were used: thermostatic incubator (for $\mathrm{T}=37^{\circ} \mathrm{C}$ ); UV lamp; Olympus BX40 microscope; cooling centrifuge; automatic micropipettes.

The consumables used were: large and small sterile tips; test tube; Petri dishes; microscope slides.

For each type of sample (Ti4, Ti-6Al-4V), two powder concentrations in culture medium were used: 1.5 $\mathrm{mg} / \mathrm{ml}, 3 \mathrm{mg} / \mathrm{ml}$. The analysis was performed using a negative control. Each test was performed in duplicate.

\section{Methods}

\section{Cell proliferation analysis}

Cytotoxicity was evaluated by placing materials in cell cultures and analyzing cell proliferation in the created environments. Specifically, it is important to demonstrate that cells in the lymphocyte culture have undergone cell division, so it is necessary to measure the RICC (Relative Increase in Cell Count) index.

The RICC index (Relative Increase in Cell Count) or the evaluation of cytotoxicity on the relative increase of the number of cells, is calculated as follows:

$R I C C=\frac{\text { The growth of the cells number in treated cultures }}{\text { The growth of the cells number in control cultures }} \times 100$

Cytotoxicity $=100-$ RICC

Micronucleus test

The in vitro micronucleus test was performed according to OECD guideline 487 .

The lymphocyte culture was transferred to a tube containing $7 \mathrm{ml}$ of supplemented PB-MAX medium to induce cell division before exposure to the chemical. Subsequently, the following steps were completed: 
a. The culture was incubated at $37^{\circ} \mathrm{C}$ for 24 hours.

b. Ti4 and Ti6Al4V powders were introduced into the lymphocyte culture 24 hours after the start of the culture. Two concentrations of $1.5 \mathrm{mg} / \mathrm{ml}$ and $3 \mathrm{mg} / \mathrm{ml}$ were tested for each type of sample. A negative control sample (no alloy/Ti powders) was also used. Each test was performed in duplicate.

c. Cultures were sacrificed 72 hours after the addition of the test materials, sufficient time for the cells to undergo several rounds of cell division so that potential DNA damage in the form of micronuclei in the interphase cells could be identified.

d. Culture was performed without the addition of cytochalasin B (cytoB - actin polymerization inhibitor).

e. In the following steps, the cultures were sacrificed by hypotension in $0.075 \mathrm{M} \mathrm{KCl}$ solution and the cells were fixed in 3:1 methanol/acetic acid solution.

f. Making microscopic preparations on microscope slides and staining them in Giemsa solution.

g. The analysis of the microscopic preparations was performed under an optical microscope.

\section{RESULTS}

Samples with high concentrations of metal powders in the environment cannot be used for genotoxicity assessment because they exceed the maximum permitted concentrations for a correct assessment without false positive results. Culture agglutination and precipitation are also found, so that cell proliferation is blocked.

\section{Cell proliferation analysis}

The cytotoxicity was calculated for each concentration and as shown in Table 1, the concentration of $3 \mathrm{mg} / \mathrm{ml}$ in the sample is close to the maximum allowed cytotoxicity, for a correct evaluation without false positive results. If the cytotoxicity exceeds $60 \%$, it causes the appearance of micronuclei as a side effect of cytotoxicity, so that the incidence of micronuclei cannot be assessed due to the genotoxic capacity of the substance.

TABLE 1. Cytotoxicity of nanoparticles depending on the concentration and obtaining method

\begin{tabular}{|c|c|c|}
\hline \multirow{2}{*}{ Type of probe } & \multicolumn{2}{|c|}{$\begin{array}{l}\text { The concentration of titanium and its alloy } \\
\text { in the culture medium }\end{array}$} \\
\hline & $1.5 \mathrm{mg} / \mathrm{ml}$ & $3 \mathrm{mg} / \mathrm{ml}$ \\
\hline $\mathrm{Ti} 4$ & $34.2 \%$ & $49.8 \%$ \\
\hline Ti6Al4V & $39 \%$ & $58.2 \%$ \\
\hline
\end{tabular}

\section{Micronuclei incidence analysis}

The in vitro micronucleus test is a test that evaluates genotoxicity by detecting micronuclei in the cyto- plasm of interphase cells. Micronuclei are acentric fragments, centromere-free that cannot migrate to the poles during cell division anaphase due to the fact that they cannot cling to the fibers of the division spindle.

TABLE 2. Analysis of micronuclei frequency according to the concentration in the culture medium

\begin{tabular}{|c|c|c|}
\hline \multirow{2}{*}{ Type of probe } & $\begin{array}{c}\text { Micronuclei incidence in lymphocyte } \\
\text { cultures depending on the concentration } \\
\text { of metal powders }\end{array}$ \\
\cline { 2 - 3 } & $1.5 \mathrm{mg} / \mathrm{ml}$ & $3 \mathrm{mg} / \mathrm{ml}$ \\
\hline Ti4 & $2 \% \circ$ & $4 \% \circ$ \\
\hline Ti6Al4V & $6 \% \circ$ & $10 \% \circ$ \\
\hline Negative control & \multicolumn{2}{|c|}{$1 \% \circ$} \\
\hline
\end{tabular}

The micronuclei incidence evaluation was performed by averaging the frequency of micronuclei per 1,000 viable nuclei, for the two replicates. 5 slides from each sample were analyzed in duplicate (5/replica/ sample).

The experiments in this study showed the presence of micronuclei, even at low concentrations. It should also be noted that micronuclei occur in a low frequency in the culture of lymphocytes considered negative control. The appearance of micronuclei is a normal effect of stress induced by the culture medium and the in vitro experiment.

At a concentration of $1.5 \mathrm{mg} / \mathrm{ml}$, the lowest incidence of micronuclei was found in Ti4 (Figure 1-3).

At the same concentration, $1.5 \mathrm{mg} / \mathrm{ml}$, a higher incidence of micronuclei was found in the Ti-6Al-4V alloy (Figure 6-7).

At a concentration of $3 \mathrm{mg} / \mathrm{ml}$, the presence of $\mathrm{mi}$ cronuclei, bridges between micronuclei and nuclei, the presence of nuclear sprays and atypical nuclei, due to the high concentration of alloy powder, compared to the negative control (Figure 4-5, Figure 8-11).

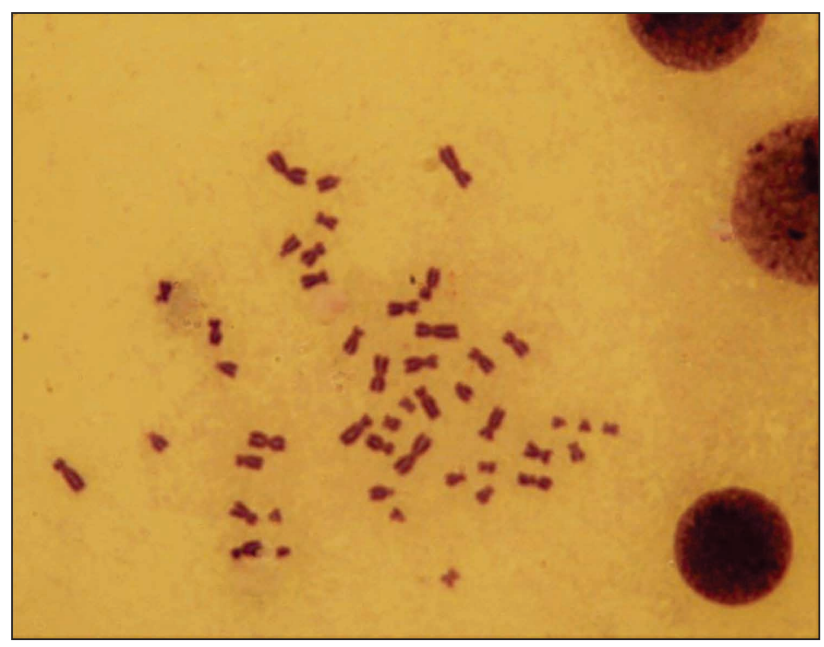

FIGURE 1. Negative control. Metaphase with normal human chromosomes and normal nuclei (X100) 


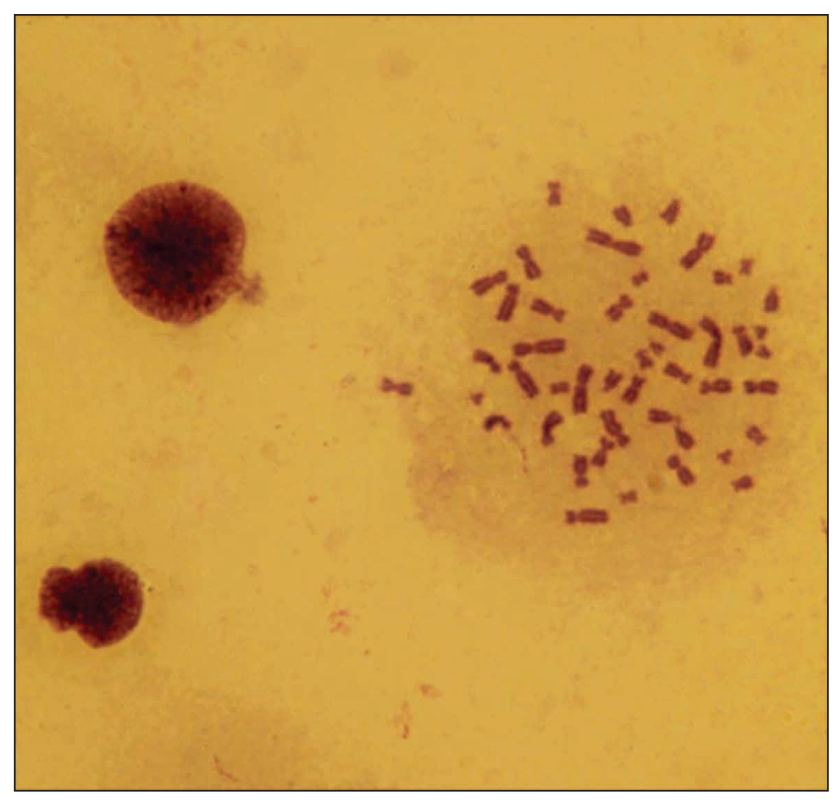

FIGURE 2. Interphase nuclei with micronuclei and metaphase with normal chromosomes - Ti4 concentration $1.5 \mathrm{mg} / \mathrm{ml}$ (x100)

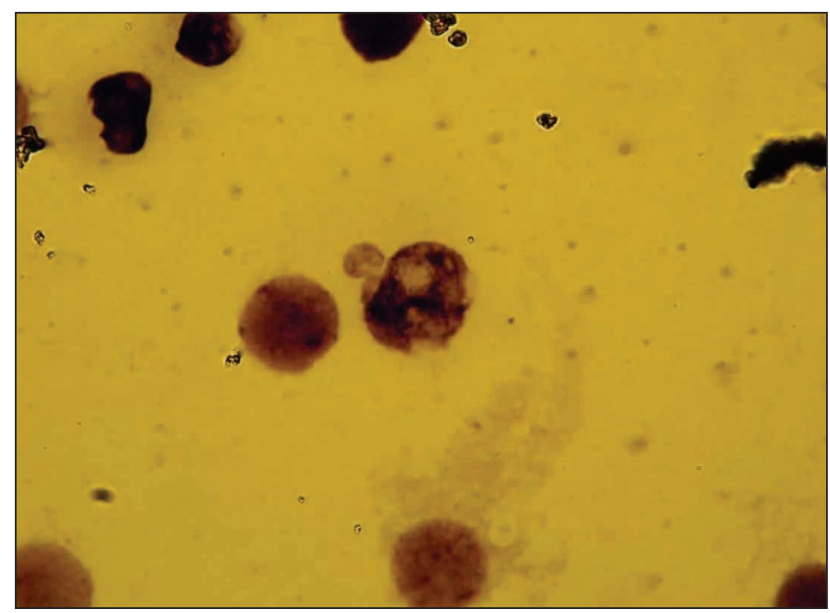

FIGURE 3. Micronucleus in the culture of lymphocytes from the Ti4 powder sample concentration $1.5 \mathrm{mg} / \mathrm{ml}$ (X100)

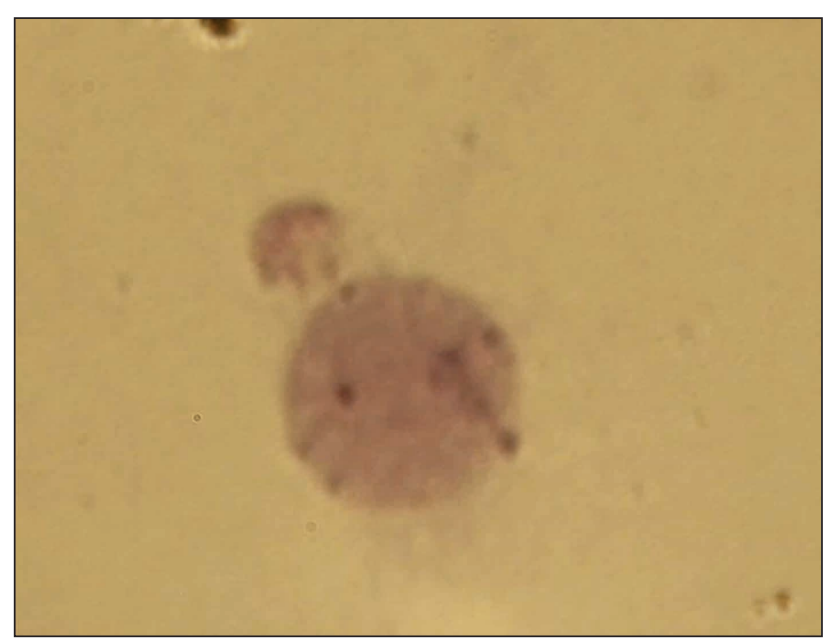

FIGURE 4. Micronucleus in the culture of lymphocytes with Ti4 powder concentration $3 \mathrm{mg} / \mathrm{ml}$ (X100)

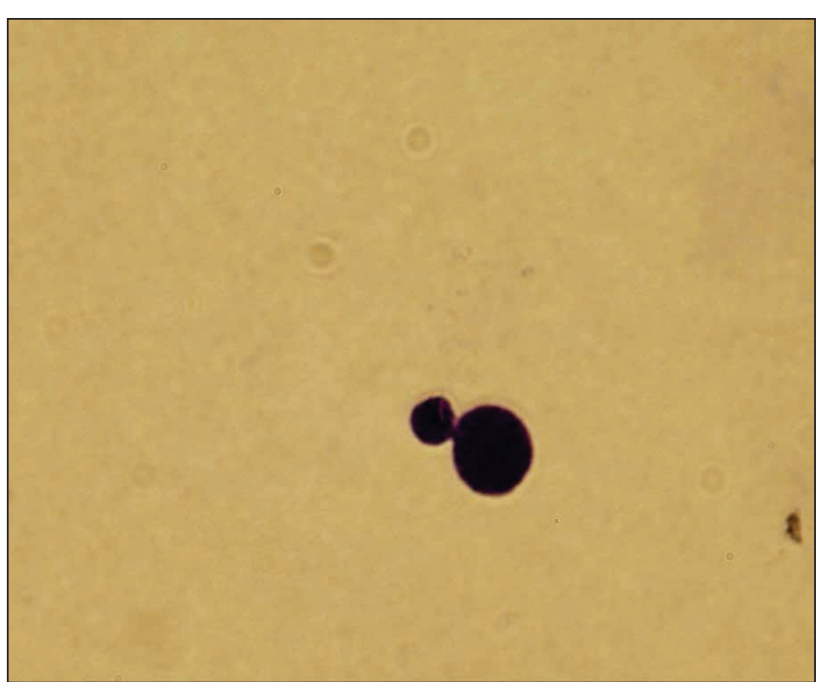

FIGURE 5. Micronucleus in the culture of lymphocytes with Ti4 powder concentration $3 \mathrm{mg} / \mathrm{ml}$ (X60)

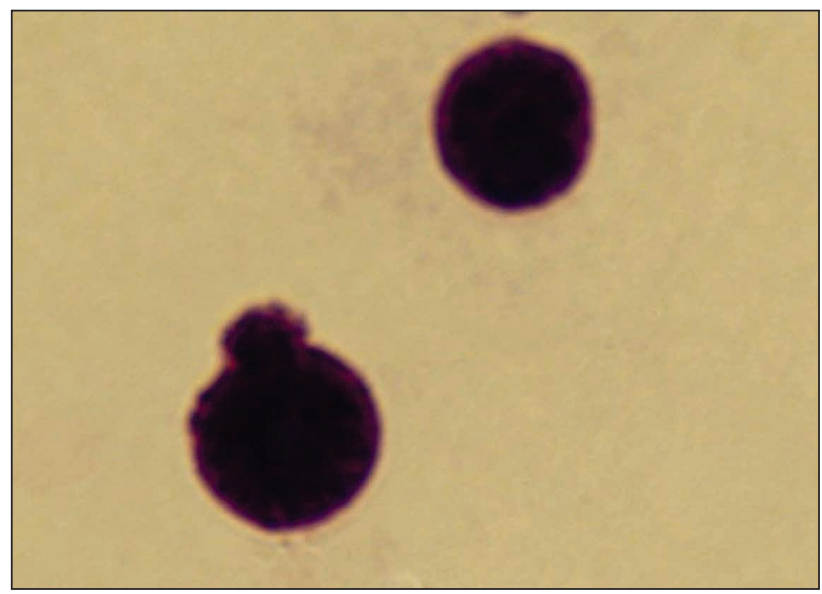

FIGURE 6. Micronucleus in culture from lymphocyte culture incubated with Ti-6Al-4V alloy powder concentration $1.5 \mathrm{mg} /$ $\mathrm{ml}(X 100)$

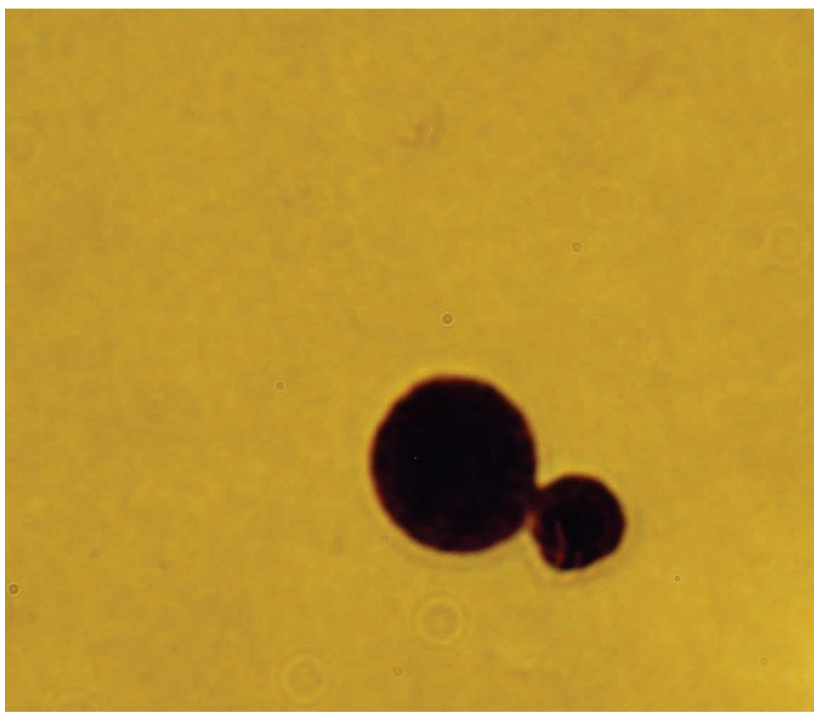

FIGURE 7. Micronucleus in formation of lymphocyte culture incubated with Ti-6Al-4V alloy powder concentration $1.5 \mathrm{mg} /$ $\mathrm{ml}(\mathrm{X100)}$ 


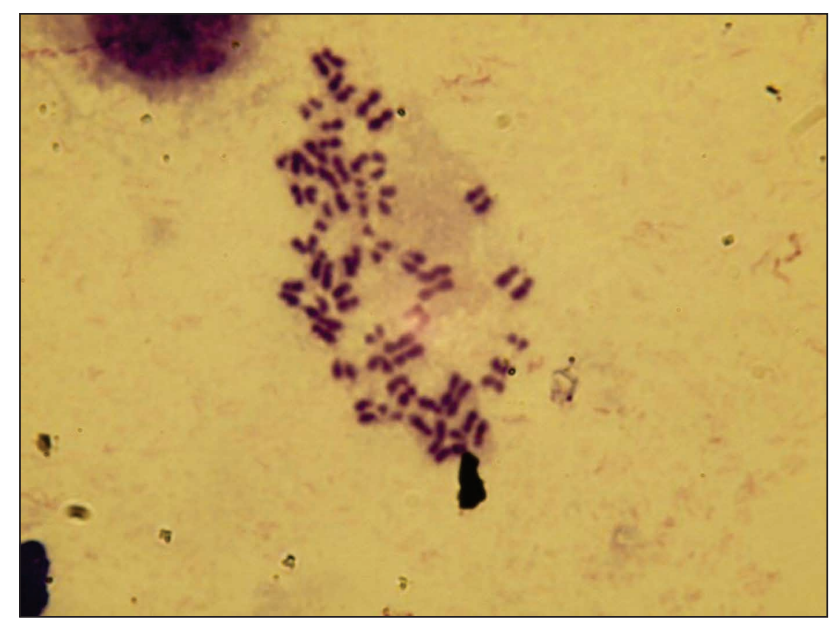

FIGURE 8. Endomitosis in the culture of lymphocytes incubated with Ti-6Al-4V alloy powder concentration $3 \mathrm{mg} / \mathrm{ml}$. The presence of double minute (DM) formations (X100) is noted.

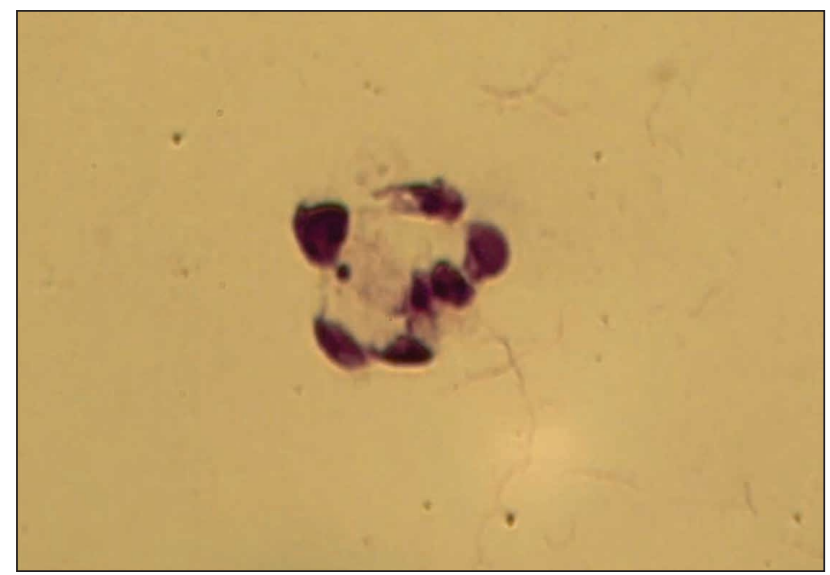

FIGURE 9. Atypical nuclei and micronucleus in the culture of lymphocytes incubated with Ti-6Al-4V alloy powder concentration $3 \mathrm{mg} / \mathrm{ml}$ (X60)

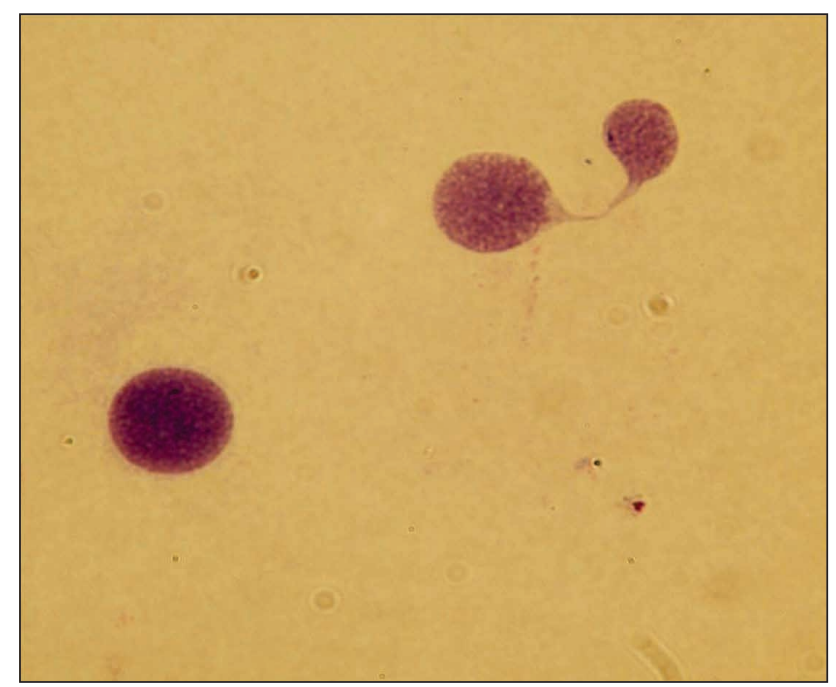

FIGURE 10. Bridges of genetic material between the nucleus and the micronucleus in the culture of lymphocytes incubated with Ti-6Al-4V alloy powder concentration $3 \mathrm{mg} / \mathrm{ml}$ (X100)

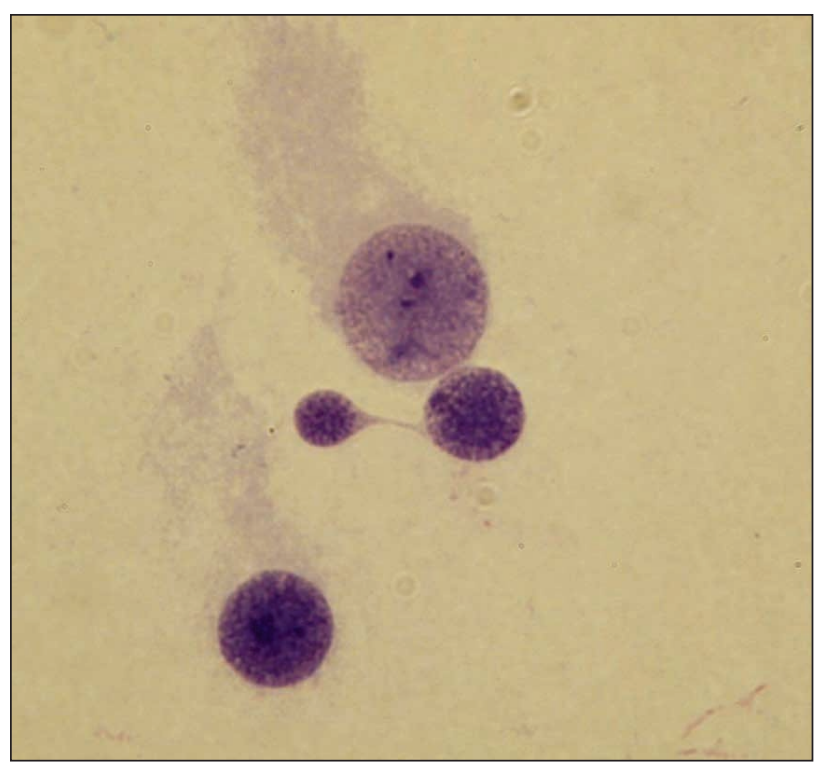

FIGURE 11. Bridges of genetic material between the nucleus and the micronucleus in the culture of lymphocytes incubated with Ti-6Al-4V alloy powder concentration $3 \mathrm{mg} / \mathrm{ml}$ (X100)

The concentration of $1.5 \mathrm{mg} / \mathrm{ml}$ of Ti4 in culture medium did not determine an increased incidence of micronuclei, compared to the negative control (Figure 1), and represents a favorable concentration for the evaluation of genotoxic capacity (Figure 2, Figure 3).

These metals, such as titanium and its alloys, have particular physical and chemical properties, causing a specific interaction with the genetic material, especially in division. During division, the nucleus is not protected by the cell membrane and thus facilitates the interactions of metals and/or alloys and genetic material.

Cytotoxicity analysis showed a lower cell proliferation compared to the negative control. From the analysis of slides prepared for the microscope, it was found that the Ti-6Al-4V alloy can make direct connections with DNA causing the appearance of micronuclei, bridges of genetic material (Figure 10, Figure 11), but also the appearance of atypical nuclei (Figure 9).

The presence of endomitosis (Figure 8) and double minute formations, markers that usually appear as a result of a very high toxicity of exogenous factors (they are especially characteristic of ionizing radiation, but not only) shows that this concentration is still too high, for a correct assessment of genotoxicity.

Analysis of micronuclei incidence for the concentration of $3 \mathrm{mg} / \mathrm{ml}$ of Ti-6Al-4V alloy, indicated a higher degree of genotoxicity and the presence of coarse lesions in the genetic material (Figure 8-11).

Endomitosis is a variant of endoreduplication, in which cells replicate chromosomes during the $S$ phase, but go through mitosis prematurely. Instead of being divided into two new nuclei, daughter, the replicated chromosomes are retained in the original nucleus (8). Endoreduplication (or endoreplication) occurs when 
chromosomes duplicate, but the cell does not separate later. This process results in the appearance of polyploid cells.

Double minutes are small fragments of extrachromosomal DNA, which have been observed in a large number of human tumors, including those located in the breast, lung, ovary, colon and especially those of neuroblastoma. These fragments represent a manifestation of gene amplification during the development of tumors, which confers selective advantages for their growth and survival (9).

\section{DISCUSSIONS}

Using the micronucleus test, the potential of substances, alloys, nanoparticles to destroy genetic material in an in vitro culture can be investigated. This test can detect both aneugenicity and clastogenicity in cells that have undergone cell division, during or after exposure to the test chemicals $(10,11)$. Bacterial genotoxicity tests (e.g., Ames test) are insufficient and therefore cannot be considered relevant when testing alloys for medical use. Comet Assay and micronucleus testing are most commonly used as genotoxicity tests.

The formation of micronuclei is a way to evidence the genotoxicity, and numerous studies have shown that their occurrence is often accompanied by symptoms and medical conditions. For example, the appearance of micronuclei in male gamete cells can lead to infertility, while a large number of micronuclei in lymphocytes in female subjects is associated with complications that can lead to miscarriages $(10,11)$. Micronuclei, together with chromosomal aberrations, aneuploids and exchanges of genetic material between sister chromatids, are important markers in identifying the initiation of cancer processes $(12,13)$.

Micronuclei are fragments of genetic material, without centromere, that form during the transition between metaphase and anaphase, during mitotic cell diffusion. Micronuclei can form from a delayed chromosome (aneugenic event) or from an acentric fragment, which detaches after rupture (clastogenicity event) and will not integrate into daughter nuclei. Micronuclei scoring can also be performed on other types of cells relevant to human biomonitoring: fibroblasts, epithelial cells (11).

It is important to decipher the mechanism of the appearance of micronuclei following exposure to genotoxic agents, in order to use them as markers for the detection of diseases such as cancer, inflammation, and their treatment. The identification and decipherment of these mechanisms can be useful both for the prevention of the formation of micronuclei and their associated diseases, and for their use for therapeutic purposes (14).
In recent years, numerous studies have been conducted on the mechanism of micronuclei formation, on the incidence of micronuclei in different types of cells and tissues, as well as the effects on cells affected by genomic instability and tumorigenesis. Although micronuclei studies are a hotly debated field, there are still some gaps: whether micronuclei can restore a complete genotype in the cell and whether micronuclei can contribute to gene expression. The exact mechanism of degradation of the micronuclei content is also unclear (12).

Many researchers in the field of dental metallurgy recommend the use of Ti-6Al-4V alloy, due to superior mechanical properties, compared to commercially pure titanium, especially grade 4 , used by most companies producing screw-type dental implants (increased tensile strength, behavior much friendlier in the mouth, etc.). However, there are studies in the literature, which refer to the fact that, after a certain period after the osseointegration of dental implants, the presence of concentrations with a certain variability of aluminum and vanadium ions in the peri-implant tissue was observed, and went even to the study of tissues located at a greater distance from these peri-implant tissues, but without significant notable preliminary results (15-18).

Thus, in the case of aluminum, intoxications with this metal compound are encountered in everyday practice quite often. The main route of entry into the body is the respiratory tract, by inhalation. Aluminum compounds are absorbed slowly, the target organ being the brain (19). Aluminum in large quantities can negatively influence bone metabolism (in very large quantities, aluminum alters the mineralization of the bone system, thus causing pathological fractures) (20). Regarding alumina - Al2O3, the main compound of aluminum, it can be stated that it has no toxic effect, due to its low solubility, even favoring cell proliferation (21).

As for vanadium, its level in the human body is very low (18). According to specialists, vanadium has a beneficial effect on physiological effects, such as: growth, lipid metabolism, bone and tooth mineralization. As toxic effects of vanadium, we can notice: the decrease of coenzyme $A$ and $Q$ concentrations, by disinhibiting oxidative phosphorylation. At the same time, vanadium can interfere with multiple enzymatic systems and can induce irreversible disturbances. Its high solubility contributes, of course, to the toxic effects, which are estimated to be 10 times higher than that of the $\mathrm{Ni}-\mathrm{Co}-\mathrm{Cu}$ complex. However, its presence in low concentrations (1-4\%) in the Ti-6Al-4V alloy, does not seem to induce major toxic reactions, but produces certain toxic phenomena, which on long term can cause harmful reactions on the human body. Specifically, in cell culture systems, titanium was well tolerated, but not vanadium, one of its main alloying metals (22-27). 
As a result, many researchers believe that the Ti-6Al-4V alloy should be abandoned for industrial-scale manufacturing of screw-type dental implants and continue to recommend the use of commercially pure titanium, especially grade 4 , as well as new compounds based on zirconium oxide, or why not, the implementation of binary applications based on $\mathrm{Ti}$ and $\mathrm{Zr}$ (Ti-Zr alloys), with an extremely promising biocompatibility and corrosion resistance and a very high applicability in the medical field, including in the implant-prosthetic rehabilitation both for making screw-type dental implants and for performing implant-supported prosthetic restorations [see already the existence on the market of a dental implant with a composition of approximately $13-18 \% \mathrm{Zr}$ and the rest $\mathrm{Ti}$ (Straumann ROXOLID, Switzerland)] (28).

\section{CONCLUSIONS}

Analysis of the genetic material and the incidence of micronuclei in vitro in human lymphocyte cultures for titanium powder (in our case Ti4) and its Ti-6Al-4V alloy with two variations of the concentration in the culture medium $(1.5 \mathrm{mg} / \mathrm{ml}$ and $3 \mathrm{mg} / \mathrm{ml})$, highlighted the presence of alterations in the genetic material ( $\mathrm{mi}$ cronuclei, atypical nuclei, bridges, endomitosis with the appearance of double minutes) and increased cytotoxicity, especially for the concentration of $3 \mathrm{mg} / \mathrm{ml}$. Even at the lowest concentration of $1.5 \mathrm{mg} / \mathrm{ml}$, there was a higher incidence of micronuclei in the Ti-6Al-4V alloy compared to the negative control, but also compared to the commercially pure titanium (in our case Ti4).

A detailed analysis of the interactions between these alloys and biological systems is imperative, as these metal alloys are of significant interest for the development of new safe biomaterials, which are very important in preventive and restorative medicine and to prevent infections forming on medical devices, which is one of the main causes of nosocomial infections. Detailed studies are also needed to correlate the essential properties of alloys, such as porosity, roughness, surface polarity, and chemical composition, with their effects on biological structures.

\section{Acknowledgement}

In this article, all the authors have equal contribution with the first author.

Conflict of interest: none declared Financial support: none declared

\section{REFERENCES}

1. Council Directive 93/42/EEC. EUR-Lex. Available at: https://eur-lex.europa.eu/ legal-content/GA/TXT/?uri= CELEX\%3A01993L0042- 20071011.

2. Wikipedia. Tabelul periodic al elementelor. Available at: https://ro.wikipedia.org/wiki/ Tabelul_periodic_al_elementelor.

3. Popovici IA. Memoriu etapa 1 carla. Tehnomedimplan.ro. Available at: http://www. tehnomedimplant.ro/memoriu-etapa-1-carla. pdf

4. Sakaguchi RL, Powers JM. Craig's Restorative dental materials. 13th ed. Philadelphia: Elsevier Mosby, 2012:231-233.

5. Piszczek P, Radtke A, Ehlert M, et al. Comprehensive Evaluation of the Biological Properties of Surface-Modified Titanium Alloy Implants. J Clin Med. 2020;9(2):342.

6. Velasco-Ortega E, Jos A, Cameán AM, et al. In vitro evaluation of cytotoxicity and genotoxicity of a commercial titanium alloy for dental implantology. Mutat Res. 2010;702(1):17-23.

7. Burlibasa L, Chifiriuc MC, Lungu MV, et al. Sythesis, physico-chemical characterization, antimicrobial activity and toxicological featurs of $\mathrm{Ag}-\mathrm{ZnO}$ nanoparticles. Arab J Chem. 2020;13(2):4180-4197.

8. Lee HO, Davidson JM, Duronio RJ. Endoreplication polyploidy with purpose. Genes Dev. 2009;23(21):2461-2477.
9. Masters J, Keeley B, Gay H, Attardi G. Variable content of double minute chromosomes is not correlated with degree of phenotype instability in methotrexateresistant human cell lines. Mol Cell Biol. 1982;2(5):498-507.

10. Fenech M. Micronuclei and their association with sperm abnormalities, infertility, pregnancy loss, pre-eclampsia and intra-uterine growth restriction in humans. Mutagenesis. 2011;26(1):63-67.

11. Kirsch-Volders M, Fenech M. Inclusion of micronuclei in non-divided mononuclear lymphocytes and necrosis/apoptosis may provide a more comprehensive cytokinesis block micronucleus assay for biomonitoring purposes. Mutagenesis. 2001;16(1):51-58.

12. Luzhna L, Kathiria P, Kovalchuk $O$. Micronuclei in genotoxicity assessment: from genetics to epigenetics and beyond. Front Genet. 2013;4:131.

13. Tucker JD, Preston RJ. Chromosome aberrations, micronuclei, aneuploidy, sister chromatid exchanges, and cancer risk assessment. Mutat Res. 1996; 365(1-3): 147-159.

14. Aypar U, Morgan WF, Baulch JE. Radiationinduced epigenetic alterations after low and high LET irradiations. Mutat Res. 2011;707(1-2):24-33.
15. Van der Cruyssen F, de Faria Vasconcelos $\mathrm{K}$, Verhelst PJ, et al. Metal debris after dental implant placement: A proof-of-concept study in fresh frozen cadavers using MRI and histological analysis. Int J Oral Implantol (Berl). 2019;12(3):349-356.

16. Fretwurst T, Buzanich $G$, Nahles $S$, et al. Metal elements in tissue with dental peri-implantitis: a pilot study. Clin Oral Implants Res. 2016;27(9):1178-1186.

17. Fretwurst T, Nelson K, Tarnow DP, et al. Is Metal Particle Release Associated with Peri-implant Bone Destruction? An Emerging Concept. J Dent Res. 2018;97(3):259-265.

18. Alrabeah GO, Knowles JC, Petridis H. The effect of platform switching on the levels of metal ion release from different implantabutment couples. Int J Oral Sci. 2016;8(2):117-125.

19. Shaw CA, Tomljenovic L. Aluminum in the central nervous system (CNS): toxicity in humans and animals, vaccine adjuvants, and autoimmunity. Immunol Res. 2013; 56(2-3):304-316.

20. Ochmański W, Barabasz W. Aluminum occurrence and toxicity for organisms. Przegl Lek. 2000;57(11):665-668.

21. Lee J, Jeon H, Haidar A et al. Recombinant Phage Coated 1D Al2O3 Nanostructures for Controlling the Adhesion and Proliferation of 
Endothelial Cells. Biomed Res Int. 2015;2015:909807.

22. Totu EE, Cristache CM, Islidak I, et al. Preliminary studies on cytotoxicity and genotoxicity assessment of the PMMA-TiO2 nanocompozites for stereolithographic complete dentures manufacturing. Rev Chim. 2018; 69(5):1160-1165.

23. Cristache CC, Totu EE, Burlibasa M, et al. Preliminary study on genotoxicity assessment of an innovative topical treatment for periodontal disease. Rev Chim. 2020;71:145-150.

24. Jamous S, Burlibașa L. New insights in molecular analysis of gene regulation-an epigenetic overview. Lett Appl Nanobioscience. 2018;7(1-2):511-522.

25. Esian D, Man A, Burlibasa L, et al. Salivary level of Streptococcus mutans and Lactobacillus spp. Related to a high risk of caries disease. Rom Biotechnol Lett. 2017;22(2):12496-12503.
26. Popescu SM, Popescu FD, Burlibaşa L. In vitro biocompatibility of zirconia. Met Int. 2010;15(4):14-26.

27. Mocuța D, Popovici IA, Burlibașa L et al. Impact of the living conditions on population health. Met Int. 2009;14:17-19.

28. Straumann. Roxolid. Available at: https:// www.straumann.com/content/dam/ media-center/straumann/en/documents/ scientific-documentation/clinicalreview/490.132-en_low.pdf. 